\title{
Melatonin induces the apoptosis and inhibits the proliferation of human gastric cancer cells via blockade of the AKT/MDM2 pathway
}

\author{
JUN SONG ${ }^{1,3,7}$, SAI-JUN MA ${ }^{2}$, JIAN-HUA LUO ${ }^{3,7}$, HUI ZHANG ${ }^{4}$, RI-XIONG WANG ${ }^{5}$, \\ HUI LIU ${ }^{6,7}$, LI LI ${ }^{1,3,7}$, ZHI-GUANG ZHANG ${ }^{1,3,7}$ and RUI-XIANG ZHOU ${ }^{3,6,7}$ \\ ${ }^{1}$ Department of Cell Biology and Genetics, ${ }^{2}$ Clinical Laboratory, Second Inpatient Department, \\ Fuzhou General Hospital; ${ }^{3}$ Key Laboratory of Ministry of Education for Gastrointestinal Cancer; \\ ${ }^{4}$ Fujian Center for Safety Evaluation of New Drugs, Fujian Medical University; ${ }^{5}$ Department of Chemotherapy, \\ The First Affiliated Hospital, Fujian Medical University; ${ }^{6}$ Department of Human Anatomy, Histology and Embryology; \\ ${ }^{7}$ School of Basic Medical Sciences, Fujian Medical University, Fuzhou, Fujian 350108, P.R. China
}

Received August 28, 2017; Accepted February 15, 2018

DOI: $10.3892 /$ or.2018.6282

\begin{abstract}
Globally, gastric cancer (GC) is one of the most common types of cancer and the third leading cause of cancer-related death. In China, gastric and liver cancers have the highest mortality rates. Melatonin, also known as $N$-acetyl-5-methoxytryptamine, is a hormone that is produced by the pineal gland in animals and regulates sleep and wakefulness. Melatonin has been shown to inhibit various carcinomas, including GC. There are many different hypotheses to explain the anticancer effects of melatonin, including stimulation of apoptosis, inhibition of cell growth, regulation of anticancer immunity, induction of free-radical scavenging, and the competitive inhibition of estrogen. However, the underlying mechanism by which these effects are elicited remains elusive. The aim of the present study was to investigate the effects of melatonin on human GC cells and determine the underlying molecular mechanism. We treated SGC-7901 GC cells with melatonin and analyzed the resulting protein changes using protein chip technology. Several proteins related to cell apoptosis and proliferation were identified and further tested in SGC-7901 GC cells. We found that melatonin induced cell cycle arrest and the downregulation of CDC25A,

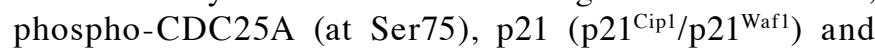
phospho-p21 (at Thr145). Melatonin also induced upregulation
\end{abstract}

Correspondence to: Professor Rui-Xiang Zhou, Department of Human Anatomy, Histology and Embryology, School of Basic Medical Sciences, Fujian Medical University, 1 Xueyuan Road, Fuzhou, Fujian 350108, P.R. China

E-mail: zhourx@mail.fjmu.edu.cn

Abbreviations: GC, gastric cancer; MLT, melatonin

Key words: melatonin, gastric cancer cells, molecular mechanism, MDM2 of Bax, downregulation of Bcl-xL, an increase in cleaved caspase-9 level and activation of caspase-3, which confirmed the involvement of the mitochondria in melatonin-induced apoptosis. Upstream regulators of the above proteins, MDM2, phospho-MDM2 (at Ser166) and AKT, phospho-AKT (at Thr308) were all attenuated by melatonin, which led to an increase in $\mathrm{p} 53$. The present study demonstrated that the oncostatic effects of melatonin on SGC-7901 GC cells are mediated via the blockade of the AKT/MDM2 intracellular pathway.

\section{Introduction}

Gastric cancer (GC) is currently the fifth most common cancer worldwide (1). As reported in the World Health Organization's World Cancer Report, there were an estimated 22,220 new cases of GC (7\% of all new cancer diagnoses) and 10,990 deaths from GC (9\% of all cancer-related deaths) globally in 2014. In China, gastric and liver cancers have the highest mortality rates; the incidence of new cases of GC is second only to that of liver cancer (2).

Melatonin ( $N$-acetyl-5-methoxytryptamine) biosynthesis is initiated by the uptake of the essential amino acid tryptophan by the pineal gland. Melatonin possesses diverse physiological functions, including regulation of circadian rhythms, controlling the maturation of the reproductive system and promoting skeletal growth; melatonin also has antitumor, immunomodulatory, antioxidant and free-radical scavenging activities $(3,4)$. Many tissues and organs have the ability to synthesize melatonin in addition to the pineal gland, including the retina, striatum, spleen, liver and gastrointestinal tract (5). In the gastrointestinal tract, for example, the amount of melatonin produced far exceeds that produced by other organs: Approximately 400 times higher than that in the pineal gland, with concentrations 10-100 times higher than those found in plasma (6). Cells of gastrointestinal tissues not only have the ability to secrete melatonin but also express melatonin receptors. Melatonin exerts important protective 
and regulatory effects via autocrine and paracrine activities in the gastrointestinal tract. A previous study found that melatonin enhances the immune system of the gut (7), regulates fecal water content, reduces peristalsis, and prevents gut damage due to digestive enzymes, hydrochloric acid (6) and exogenously administered drugs (8).

In previous studies, melatonin was found to inhibit various carcinomas, such as GC (9-13), liver (14-17), breast (18-21), oral $(22,23)$ and prostate cancer $(24-26)$. Melatonin exerts anticancer effects by promoting cellular apoptosis, inhibiting cell growth, regulating anticancer immunity, scavenging free radicals and competitively inhibiting estrogen. However, the mechanism by which melatonin exerts these effects is unclear. Our previous studies found that melatonin exhibited effective anticancer effects that were mediated by the stimulation of apoptosis, inhibition of cell growth, and reduction in the number of $\mathrm{CD}^{4+} \mathrm{CD}^{25+}$ regulatory $\mathrm{T}$ cells in mouse $\mathrm{GC}$ cells and in vivo $(27,28)$. We also found that the nuclear receptor ROR $\gamma$ is involved in the effects of melatonin on human GC cells $(12,13)$. A recent study demonstrated that melatonin induces AGS cell apoptosis via the activation of JNK and p38, and the suppression of NF- $\kappa \mathrm{B}$ (13). To further elucidate the effects of melatonin on human GC cells and the molecular mechanism involved, we selected the human GC cell line SGC-7901 and analyzed the resulting changes in proteins using protein chip technology. Several proteins related to apoptosis and cell proliferation were identified and further tested in SGC-7901 cells, including AKT, MDM2, CDC25A, p53, p21, Bcl-xL and Bax. Both CDC25A and p21 are known to regulate cell cycle progression via their interactions with cyclin/CDK complexes. Bcl-xL and Bax are both mitochondrial proteins that control the release of cytochrome $c$ and are involved in mitochondrial apoptosis. AKT, MDM2 and p53 are upstream regulators of the mitochondrial apoptosis pathway. The aim of the present study was to elucidate the mechanism by which melatonin elicits its anticancer effects in GC cells.

\section{Materials and methods}

Cell culture and reagents. Human GC cell line SGC-7901 was purchased from the Chinese Academy of Sciences, Shanghai Institute for Biological Science (Shanghai, China). SGC-7901 cells were cultured in Roswell Park Memorial Institute (RPMI)-1640 medium supplemented with $10 \%$ fetal bovine serum (both from GE Healthcare Life Sciences, HyClone Laboratories, Logan, UT, USA). The cultures were maintained at $37^{\circ} \mathrm{C}$ in $5 \% \mathrm{CO}_{2}$. Melatonin (Sigma-Aldrich; Merck KGaA, Darmstadt, Germany) was dissolved in ethanol prior to use. The final concentration of ethanol in the culture medium never exceeded $1 \%$.

Cell viability assays. After exposure of GC cells to various concentrations of melatonin for various times, we assessed cell viability using the MTS assay (CellTiter $96^{\circledR} \mathrm{AQ}_{\text {ueous }}$ One Solution Cell Proliferation Assay; Promega, Madison, WI, USA), which is based on the mitochondrial conversion of MTS (a tetrazolium salt) into a water-soluble, colored, formazan precipitate that can be quantified by spectrophotometry. SGC-7901 cells were seeded at a density of $1 \times 10^{4}$ cells $/ \mathrm{ml}$ in 96-well plates. After $24 \mathrm{~h}$ of culture, the cells were treated with 0 (1\% ethanol as control was added), 1, 2, 3, 4 or $5 \mathrm{mM}$ melatonin for 24, 48 or $72 \mathrm{~h}$. Absorbance of cells at $490 \mathrm{~nm}$ was measured using a microplate reader (Synergy HT; BioTek Instruments Inc., Winooski, VT, USA) when MTS was added 2 h later. Effects on SGC-7901 cell viability was measured by determining the percentage of viable cells relative to the control: $\%$ cell inhibition $=\left[1-\left(\mathrm{OD}_{\mathrm{mt}}-\mathrm{OD}_{\text {blank }}\right)\right] /$ $\left(\mathrm{OD}_{\mathrm{c}}-\mathrm{OD}_{\text {blank }}\right) \times 100 \%$, where $\mathrm{OD}_{\mathrm{mt}}$ is the average $\mathrm{OD}$ value of the melatonin-treated samples, $\mathrm{OD}_{\mathrm{c}}$ is the average $\mathrm{OD}$ value of the control samples, and $\mathrm{OD}_{\text {blank }}$ is the average $\mathrm{OD}$ value of the blank samples without cells.

Cell morphology at the microscopic and ultramicroscopic levels. SGC-7901 cells were seeded at a density of $2 \times 10^{5}$ cells $/ \mathrm{ml}$ in 6-well plates. After $24 \mathrm{~h}$ of culture, the cells were treated with $3 \mathrm{mM}$ melatonin or $1 \%$ ethanol (control) for $24 \mathrm{~h}$. Cell morphology was observed with an inverted microscope (Primo Vert; Carl Zeiss Microscopy GmbH, Jena, Germany) and an electron microscope (EM208; FEI, Hillsboro, OR, USA).

Cell cycle analysis. After treatment with melatonin, cells were collected and stained with propidium iodide (PI; BD Pharmingen; BD Biosciences, Franklin Lakes, NJ, USA). Single-cell suspensions were sorted by flow cytometry, which revealed the distribution of cells in the three major phases of the cycle $\left(\mathrm{G}_{0} / \mathrm{G}_{1}\right.$ vs. $\mathrm{S}$ vs. $\left.\mathrm{G}_{2} / \mathrm{M}\right)$.

Analysis of apoptosis. We use the TUNEL assay (DeadEnd ${ }^{\mathrm{TM}}$ Fluorometric TUNEL System; Promega) to analyze cell apoptosis in situ. This assay measures nuclear DNA fragmentation of apoptotic cells tagged with fluorescein-12-dUTP, which can be visualized by fluorescence microscopy. SGC-7901 cells were cultured on coverslips and treated with either $3 \mathrm{mM}$ melatonin or $1 \%$ ethanol for $24 \mathrm{~h}$. After three washes with phosphate-buffered saline, the cells were fixed in $4 \%$ paraformaldehyde and incubated at $4^{\circ} \mathrm{C}$ for $25 \mathrm{~min}$. Fixed cells were permeabilized with $0.2 \%$ Triton $\mathrm{X}-100$ solution for $5 \mathrm{~min}$. The cells were then incubated with a nucleotide mixture and rTdT buffer solution, and incubated at $37^{\circ} \mathrm{C}$ for $60 \mathrm{~min}$ to allow the tailing reaction to occur in the dark. After terminating the reaction in $2 \mathrm{X} \mathrm{SSC}$, the cells were counterstained with PI for $15 \mathrm{~min}$ at room temperature. Positive apoptotic cells were identified under 5 random fields of view by fluorescence microscopy (Axio Observer A1; Carl Zeiss Microscopy GmbH, Jena, Germany).

To analyze the rate of cellular apoptosis, we used the FITC Annexin V apoptosis detection kit I (BD Pharmingen; BD Biosciences, Franklin Lakes, NJ, USA), following the manufacturer's instructions. Briefly, SGC-7901 cells were treated with $3 \mathrm{mM}$ melatonin for $24 \mathrm{~h}$ and collected. In cells that have undergone apoptosis, phosphatidylserine (PS), which is usually located in the inner leaflet of the plasma membrane, is translocated to the outer leaflet of the plasma membrane. Once on the outer surface of the membrane, PS is bound by FITC-labeled Annexin V and detected by flow cytometry.

Protein extraction and western blot analysis. Melatonin-and vehicle-treated SGC-7901 cells were lysed in cell lysis buffer (Beyotime Institute of Biotechnology, Shanghai, China) supplemented with a protease inhibitor cocktail and phosphatase 
inhibitors (Roche, Basel, Switzerland). Protein concentrations were measured using the enhanced BCA protein assay kit (Beyotime Institute of Biotechnology). Protein extracts $(40 \mu \mathrm{g})$ were subjected to 12 or $15 \%$ polyacrylamide gel electrophoresis. The proteins in the gels were transferred to polyvinylidene difluoride membranes, which were then blocked in Tris-buffered saline containing $0.5 \%$ bovine serum albumin. Blocked membranes were incubated with primary antibodies: anti-MDM2 (cat. no. ab137413; dilution, 1:1,000), anti-phospho-MDM2 (at Ser166; cat. no. ab170880; dilution, 1:50,000), anti-CDC25A (cat. no. ab140247; dilution, 1:200), anti-phospho-CDC25A (at Ser75; cat. no. ab47279; dilution, 1:1,000), anti-p21 (cat. no. ab109199; dilution, 1:5,000), and anti-phospho-p21 (at Thr145; cat. no. ab47300; dilution, 1:1,000) were purchased from Abcam (Cambridge, UK); anti-AKT (cat. no. 4685S; dilution, 1:1,000), anti-phospho-AKT (at Thr308; cat. no. 4056S; dilution, 1:1,000), anti-Bcl-xL (cat. no. 2764S; dilution, 1:1,000), anti-Bax (cat. no. 5023P; dilution, 1:1,000), anti-caspase-9 (cat. no. 9508S; dilution, 1:1,000) and anti-GAPDH (cat. no. 2118S; dilution, 1:1,000) were purchased from Cell Signaling Technology, Inc. (Danvers, MA, USA) and anti-p53 was purchased from Medical and Biological Laboratories Co., Ltd., Nagoya, Japan (cat. no. K0181-3; dilution, 1:5,000). Proteins were detected by the addition of alkaline phosphatase-conjugated secondary antibody, goat anti-rabbit IgG (cat. no. ab98505; dilution, 1:5,000; Abcam) or goat anti-mouse IgG (cat. no. sc-2008; dilution, 1:1,000; Santa Cruz Biotechnology, Inc., Santa Cruz, CA, USA). Target proteins were visualized by the addition of CDP-Star reagents (Roche Diagnostics, Mannheim, Germany). The bands were detected using an ImageQuant LAS 4000 mini (GE Healthcare, Chicago, IL, USA). Band intensities were quantified using ImageJ $2 x$ software (National Institutes of Health, Bethesda, MD, USA) and the relative intensities to the internal GAPDH control were calculated.

Analysis of caspase-3 activity. SGC-7901 cells were seeded at a density of $1 \times 10^{4}$ cells $/ \mathrm{ml}$ in 96 -well plates. After $24 \mathrm{~h}$ of culture, the cells were treated with 0 (1\% ethanol as control) or $3 \mathrm{mM}$ melatonin for $24 \mathrm{~h}$. Melatonin- and vehicle-treated SGC-7901 cells were added together with $100 \mu \mathrm{l}$ of Caspase-Glo ${ }^{\circledR}$ 3/7 Reagent according to the caspase-Glo ${ }^{\circledR}$ 3/7 assay kit (Promega Corp., Madison, WI, USA) manufacturer's instructions. This assay provides a luminogenic caspase-3/7 substrate that is released following caspase cleavage, and the subsequent production of light can be detected by a microplate luminometer (Orion microplate luminometer; Berthold Detection Systems GmbH, Pforzheim, Germany).

Data analysis. The data represent the means \pm standard deviations (SD) from at least three independent experiments. One-way ANOVA and the Student's paired t-test were used to determine statistical significance. $\mathrm{P}<0.05$ was considered to indicate a statistically significant difference. All analyses were performed using SPSS 17.0 software (SPSS, Inc., Chicago, IL, USA).

\section{Results}

Melatonin inhibits the proliferation of SGC-7901 cells. We assessed the cell viability using the MTS assay. Results

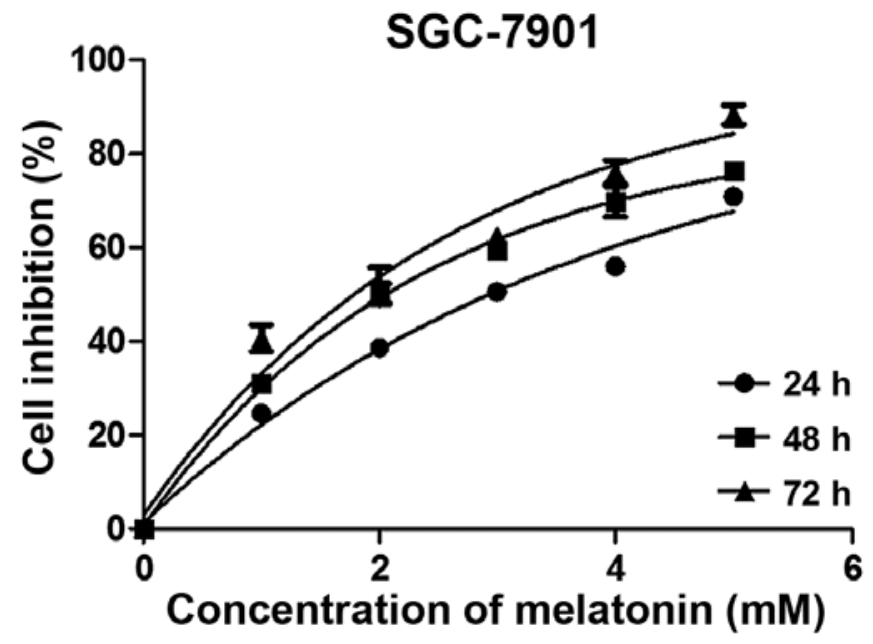

Figure 1. Percentage of cell inhibition as determined by MTS assay. SGC-7901 cells were treated with 0 ( $1 \%$ ethanol was added as control) or 1 , $2,3,4$ or $5 \mathrm{mM}$ melatonin for 24,48 or $72 \mathrm{~h}$.

demonstrated that cell growth was inhibited after melatonin exposure in a dose- and time-dependent manner (Fig. 1). Based on these results, we selected $3 \mathrm{mM}$ melatonin and $24 \mathrm{~h}$ of exposure for the follow-up experiments; these parameters reflect a $50 \%$ inhibition of cell viability. Cells treated with higher concentrations of melatonin for longer times were not suitable for use in subsequent experiments. The morphology of treated SGC-7901 cells was assessed microscopically (Fig. 2). At the microstructural level, melatonin-treated cells appeared thinner and more elongated than control cells, with twisted cytoplasmic extensions and a greater number of floating dead cells. At the ultrastructural level, apoptotic cells were evident, surface microvilli were absent, plasmolysis and nuclear pyknosis were present, mitochondria exhibited vacuolation, and apoptotic bodies appeared in the cultures of melatonin-treated cells.

Melatonin induces cell cycle arrest and apoptosis in SGC-7901 cells

Melatonin arrests $S G C-7901$ cells in the $G_{I} / S$ phase of the cell cycle. We assessed the distribution of SGC-7901 cells in various phases of the cell cycle by flow cytometry. The analysis showed that the proportion of cells in the $G_{0} / G_{1}$ phase increased from $59.357 \pm 1.518$ to $68.583 \pm 0.649 \%(\mathrm{P}<0.05)$ in the melatonin-treated SGC-7901 cells compared to the controls (Fig. 3). Consistent with this finding, the proportion of cells in the $S$ and $\mathrm{G}_{2} / \mathrm{M}$ phases decreased relative to the controls: As shown in Fig. 3, the proportion of S-phase cells decreased from $21.177 \pm 1.322$ to $16.590 \pm 1.874 \%(\mathrm{P}<0.05)$, and the proportion of $\mathrm{G}_{2} / \mathrm{M}$-phase cells decreased from $20.450 \pm 1.868$ to $14.727 \pm 1.194 \%(\mathrm{P}<0.01)$. All differences were statistically significant. These results indicate that melatonin effectively arrested SGC-7901 cells in the $G_{1} / S$ phase of the cell cycle.

Melatonin induces apoptosis in SGC-7901 cells. We used two methods to determine whether melatonin stimulates the apoptosis of SGC-7901 cells. First, we used the TUNEL assay to measure apoptotic SGC-7901 cells in situ. As shown in Fig. 4, apoptosis could be observed in the SGC-7901 cells 

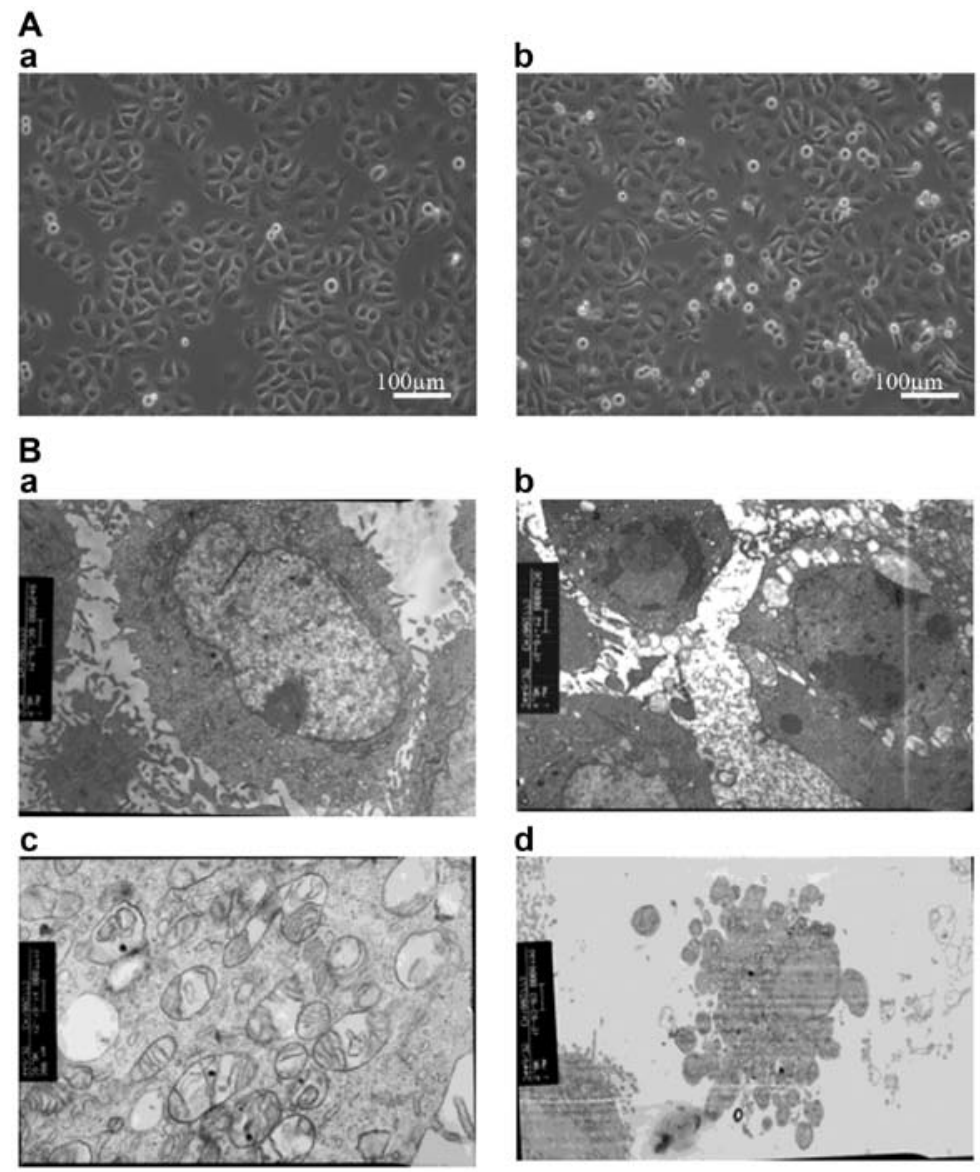

Figure 2. Microscopic examination of SGC-7901 cells treated with $3 \mathrm{mM}$ melatonin for $24 \mathrm{~h}$ compared to control cells. (A) Control cells viewed under an inverted microscope (a); melatonin-treated SGC-7901 cells viewed under an inverted microscope (b). (B) Control cells viewed by electron microscopy (a); apoptotic melatonin-treated SGC-7901 cells viewed by electron microscopy (b); vacuolation of mitochondria in apoptotic SGC-7901 cells (c); apoptotic bodies after melatonin treatment (d).

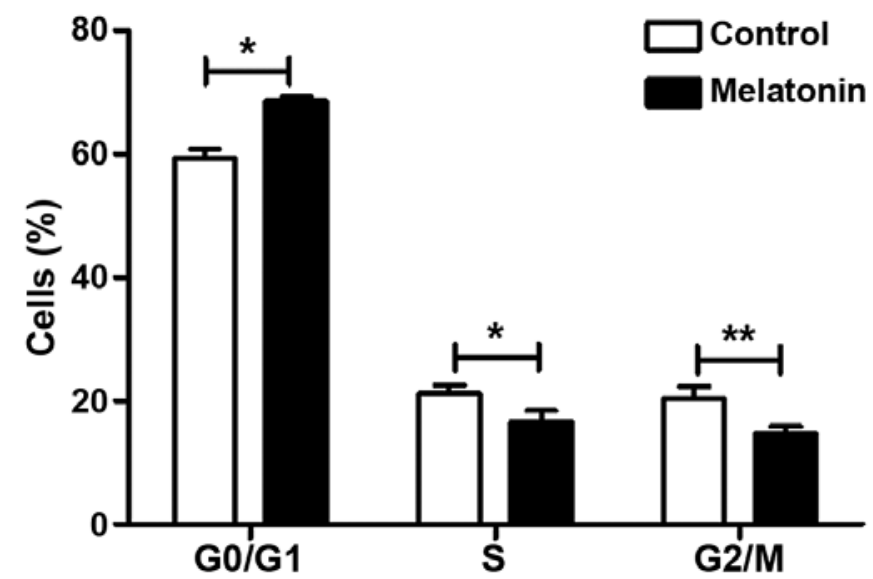

Figure 3. Cell cycle analysis of melatonin-treated SGC-7901 cells by flow cytometry. ${ }^{*} \mathrm{P}<0.05,{ }^{* *} \mathrm{P}<0.01$ vs. control.

treated with melatonin but not in the controls. We then used flow cytometry to determine the percentage of apoptotic cells using the FITC Annexin V apoptosis detection kit I. The percentages of melatonin-treated cells in the early and late stages of apoptosis were found to increase compared with the controls (Fig. 5). Early apoptotic cells increased from $0.97 \pm 0.31$ to $7.25 \pm 3.00(\mathrm{P}<0.05)$, late apoptotic cells increased from $1.23 \pm 0.53$ to $10.22 \pm 2.22(\mathrm{P}<0.05)$, and the total number of apoptotic cells increased from $2.20 \pm 0.81$ to $17.48 \pm 4.98(\mathrm{P}<0.05)$. All differences were statistically significant.

Melatonin affects proteins associated with the cell cycle and apoptosis. CDC25A and p21 are known regulators of cell cycle progression that interact with cyclin/CDK complexes. Melatonin reduced the expression of CDC25A and the level of CDC25A phosphorylation at Ser75 in SGC-7901 cells compared to the controls (Fig. 6A). Moreover, we found that both the level of p21 and its phosphorylation at Thr145 were decreased (Fig. 6B). We examined changes in apoptosis-associated proteins Bcl-xL, Bax, caspase-9 and caspase-3. In SGC-7901 cells treated with melatonin, western blot analysis showed evidence of a reduced expression level of Bcl-xL and a significantly increased expression level of Bax compared with controls (Fig. 6C). Melatonin treatment also increased cleaved caspase-9 levels and caspase-3 activity (Fig. 6G and H).

Melatonin affects the expression of upstream regulators MDM2, p53 and AKT. MDM2, p53 and AKT are upstream regulators of the apoptosis- and cell cycle-related proteins mentioned above. To further understand the molecular 

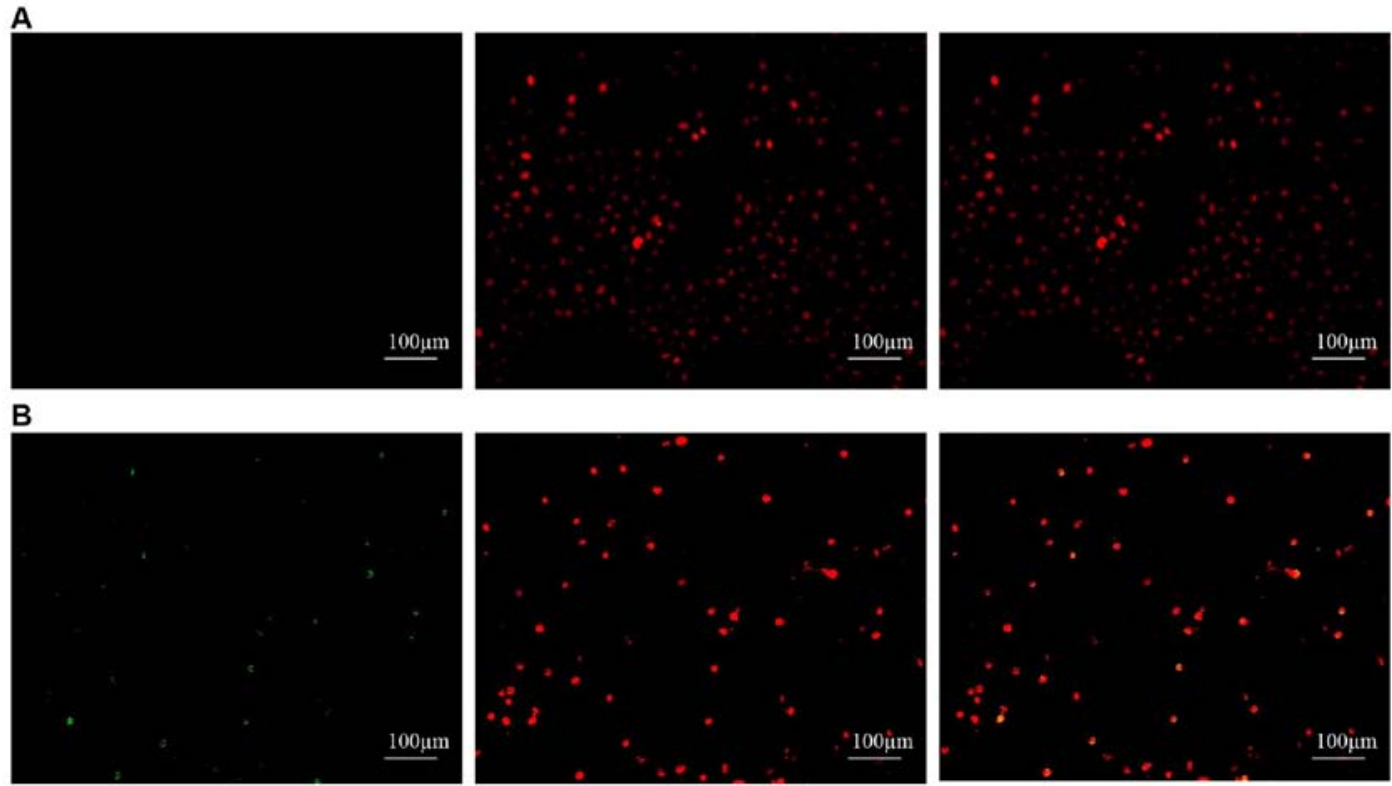

Figure 4. Analysis of apoptosis in SGC-7901 cells treated with $3 \mathrm{mM}$ melatonin for $24 \mathrm{~h}$ compared to control cells treated with $1 \%$ ethanol by fluorescence microscopy and TUNEL assay. Positive apoptotic cell nuclei appear green and yellow. (A) Control group. (B) Melatonin-treated group.
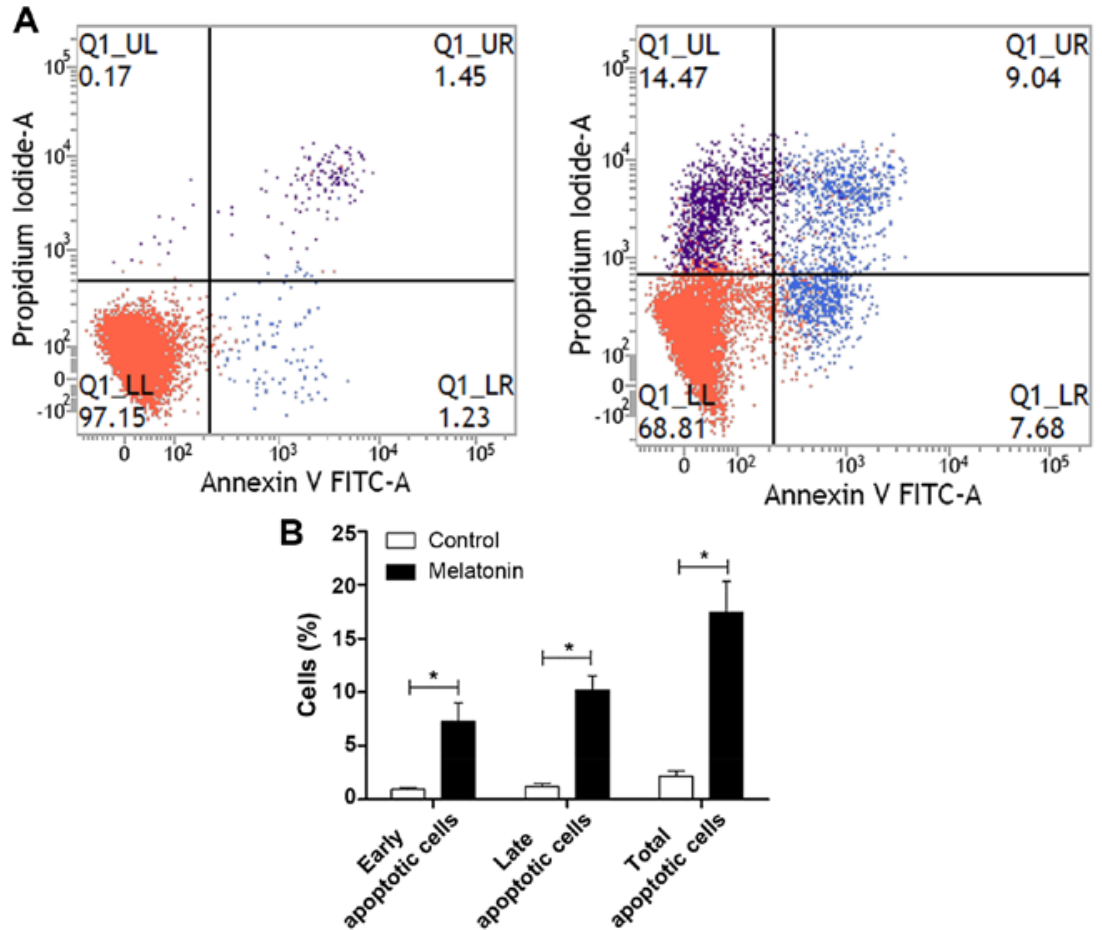

Figure 5. Analysis of apoptosis in SGC-7901 cells treated with $3 \mathrm{mM}$ melatonin for 24 h by flow cytometry. (A) Representative spectra. LL, intact cells; LR, early apoptotic cells; UR, late apoptotic cells; UL, necrotic cells. (B) Bar graph representation of the percentage of apoptotic cells. "P<0.05 vs. control.

mechanism underlying melatonin-induced cell apoptosis and inhibition of cell proliferation, we evaluated the expression levels of MDM2, p53 and AKT in SGC-7901 cells after melatonin exposure. Western blot analysis showed that the expression levels of MDM2 and phospho-MDM2 (at Ser166) were decreased compared with the controls (Fig. 6D), whereas the expression level of p53 was increased compared with the controls (Fig. 6F). Levels of both AKT and phospho-AKT (at Thr308) were decreased after melatonin treatment of SGC-7901 cells compared to the controls (Fig. 6E).

\section{Discussion}

The results of the present study confirmed that melatonin arrests SGC-7901 GC cells in the G1/S phase of the cell cycle and promotes apoptosis via a mitochondrial apoptosis pathway, involving a key factor, MDM2. We detected increased expression levels of MDM2, phospho-MDM2 (at Ser166), and the upstream regulator AKT in response to melatonin. Murine double $2 \mathrm{~min}$, also HDM) (MDM2) was originally identified as an amplified oncogene on double-minute chromosomes 


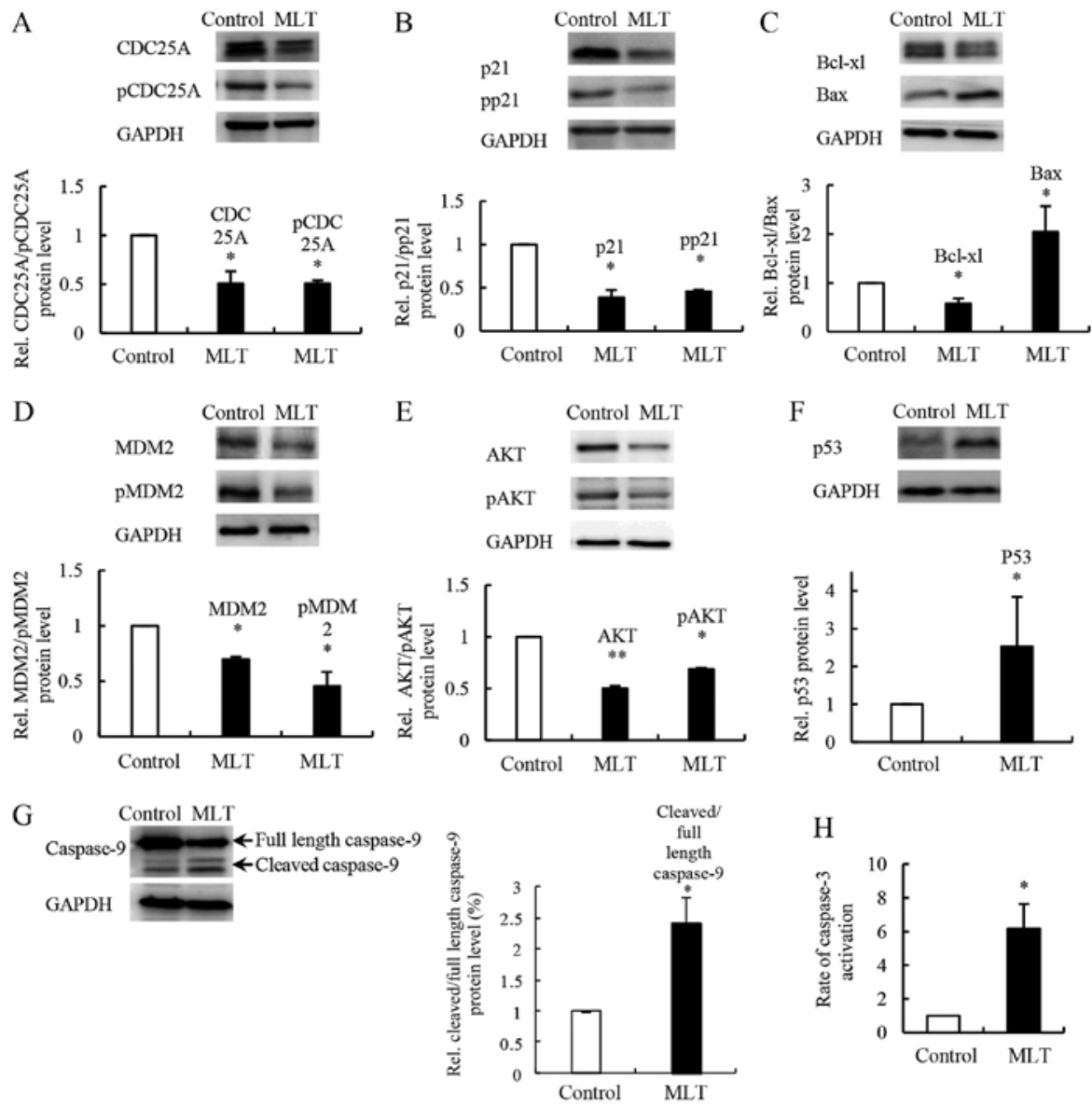

Figure 6. Analysis of expression and activation of proteins associated with cell proliferation and apoptosis. (A-G) Western blot analysis. Equal loading of proteins is illustrated by the GAPDH band. (H) Caspase- 3 activity. Data are expressed as means $\pm \mathrm{SD}$. ${ }^{*} \mathrm{P}<0.05,{ }^{* * *} \mathrm{P}<0.01$ vs. control. Data shown are representative of three independent experiments. MLT, melatonin; GAPDH glyceraldehyde 3-phosphate dehydrogenase.

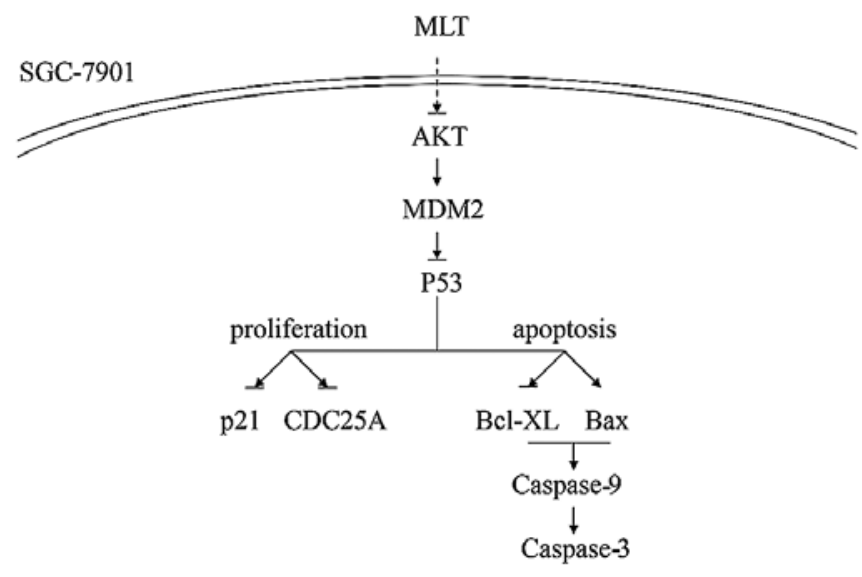

Figure 7. The signaling pathway involved in the induction of apoptosis and inhibition of cellular proliferation by melatoninin SGC-7901 cells. MLT, melatonin.

in transformed mouse fibroblasts (13). While it is involved in the regulation of gene expression as E3 ubiquitin-protein ligase, MDM2 itself is overexpressed in various human cancers (30,31), including GC (32-36). MDM2 is an important negative regulator of the $\mathrm{p} 53$ tumor suppressor. Overexpression of MDM2 promotes tumor development by suppressing the function of p53 (37). At the protein level, MDM2 increases both the polyubiquitination of p53, which drives its proteasomal degradation, and the monoubiquitination of $\mathrm{p} 53$, which exposes a nuclear export signal, leading to the cytoplasmic translocation of p53 $(38,39)$ and inhibition of its interaction with DNA (40-43). MDM2 also directly inhibits p53 transcription by binding to the transactivation domain of the p53 gene at the transcriptional level $(44,45)$. Furthermore, MDM2 inhibits p53 mRNA translation by binding the 5'-UTR of p53 mRNA, likely through interactions with ribosomal protein $\mathrm{L} 26$, a positive regulator of $\mathrm{p} 53$ expression (46). The phosphorylated form of MDM2 at Ser166 is a substrate for AKT that is activated when its Thr308 is phosphorylated by PDPK1, which increases the nuclear localization of MDM2 and the subsequent degradation of p53 (47-49). In our experiments, melatonin exposure caused the downregulation of AKT, phospho-AKT (at Thr308), MDM2, and phospho-MDM2 (at Ser166), and the upregulation of p53, suggesting that melatonin inhibits cancer cell growth by attenuating AKT activity, which leads to the inactivation of MDM2.

However, the presence of p53 mutations in cancer diminishes the ability of p53 to inhibit tumor growth. Many studies have argued that there are p53-independent effects of MDM2 $(50,51)$. MDM2 could influence the activities of other transcription factors, such as p73 (52-55), p65 (56), Smad proteins $(57,58)$, cyclin D1, c-Jun, c-Myc and pRb (E2F1) $(59,60)$. Moreover, MDM2 has been shown to influence 
chromatin modifications by interacting directly with chromatin (61-63). A p53 mutation was reported in SGC-7901 cells, but its oncostatic function was not blocked completely (64). However, this infers that other components may be involved in the melatonin-induced inhibition of GC cell growth.

In the present study, melatonin was found to affect other components of the mitochondrial apoptosis pathway downstream of MDM2 and AKT. Melatonin treatment caused a decrease in Bcl-xL levels and an increase in Bax levels, which were consistent with the results of our previous studies concerning the inhibitory effect of melatonin on the proliferation of mouse precancerous cells (28). The changes in Bcl-xL and Bax as well as the upregulation of cleaved caspase- 9 and activated caspase- 3 indicated that melatonin induced apoptosis via a mitochondrial apoptosis pathway. Cell cycle-related proteins CDC25A and p21 were also affected by melatonin treatment. CDC25A is a dual-specificity phosphatase that activates the G1/S-phase cyclin-dependent kinases CDK4 and CDK2, which are required for cell cycle progression (65). CDC25A was also found to suppress apoptosis by inhibiting ASK1 activity (66). The degradation of CDC25A by ubiquitination is blocked by the phosphorylation of CDC25A at Ser75 (67). Furthermore, $\mathrm{CDC} 25 \mathrm{~A}$ is overexpressed in a variety of tumor types, such as lung, breast, prostate and GC and is correlated with poor prognosis (68). Melatonin induces the downregulation of CDC25A and phospho-CDC25A (Ser75), causing cell cycle arrest in the G1/S phase. Surprisingly, levels of p21, a cyclin/CDK complex inhibitor, were decreased in SGC-7901 cells after melatonin treatment which was different from previous studies in mouse precancerous cells (28). However, some researchers have shown increases in $\mathrm{p} 21$ levels in response to mitogenic signals. The binding of $\mathrm{p} 21$ to cyclin/CDK forms a complex that stimulates cell cycle progression (69). Martin et al (70) also found increased p21 expression levels in C6 glioma cells treated with melatonin. Their results are consistent with those of our experiments. Moreover, Rother et al (71) proposed that p53 suppresses CDC25A expression, independent of p21, therefore, the role of $\mathrm{p} 21$ is complex and may vary in different conditions.

In conclusion, the downregulation of AKT, MDM2, and changes in the above-mentioned factors suggest that the AKT/MDM2 pathway is involved in the mechanism by which melatonin inhibits the growth of SGC-7901 GC cells (Fig. 7). Melatonin induces apoptosis and inhibits the proliferation of SGC-7901 via downregulation of AKT and MDM2, inducing an increase in p53. Previous studies suggest that p53 activates the expression of the $\mathrm{Cdk}$ inhibitor $\mathrm{p} 21$, resulting in CDC25A decrease, and cell cycle arrest in the G1/S phase. However, we found a decrease in $\mathrm{p} 21$ indicating that the CDC25A decrease is independent of p21. Further research should be conducted concerning the role of p21 in the effect of melatonin against GC SGC-7901 cell growth. There are other points needed to be tested in future studies. Firstly, the flow cytometric analysis showed that the proportion of cells in the $G_{0} / G_{1}$ phase was increased and in the $S, G_{2} / M$ phases was decreased relative to the controls. It would be better if the $G_{0}$ and $G_{1}$ phase of SGC-7901 cells are differentiated further, since there would be a few early apoptotic cells induced by the melatonin mixing with the cells of $\mathrm{G}_{0}$ phase. The conclusion that melatonin induces cell cycle arrest in $\mathrm{G}_{1} / \mathrm{S}$ would be confirmed to a higher degree removing these potential apoptotic cells. Secondly, this study analyzes only one type of human GC cell line. We are currently in the selection of more cell lines and a PDX model to confirm the anticancer effect of melatonin. The experiments are still underway and the results need further verification.

\section{Acknowledgements}

The authors would like to thank JJL and $\mathrm{ZHH}$ from the Public Technology Service Center (Fujian Medical University, Fuzhou, China) for their technical assistance.

\section{Funding}

The present study was sponsored by the Project of the Education Department of Fujian Province of China (nos. JA12153 and JAT160202), the Natural Science Foundation of Fujian Provincial Department of Science \& Technology (nos. 2016J01535 and 2017J01530), the Young and Middle-aged Key Personnel Training Program of Fujian Provincial Health and family planning commission (no. 2016-ZQN-51) and the Nursery Research Fund Project of Fujian Medical University (2015MP006).

\section{Availability of data and materials}

The datasets used and/or analyzed during the current study are available from the corresponding author on reasonable request.

\section{Authors' contributions}

RXZ was involved in the study concept and design, supervision and provided final approval of the version to be published. JS was involved in the drafting of the manuscript, the analysis and interpretation of the data, performed experiments and obtained funding. SJM, JHL and $\mathrm{HZ}$ were involved in performing experiments, analysis and interpretation of the data. RXW, HL, LL and ZGZ assisted with the experimental design, data interpretation, acquisition of funding. All authors read and approved the final manuscript.

\section{Ethics approval and consent to participate}

Not applicable.

\section{Consent for publication}

Not applicable.

\section{Competing interests}

The authors declare that they have no competing interests.

\section{References}

1. Jemal A, Bray F, Center MM, Ferlay J, Ward E and Forman D: Global cancer statistics. CA Cancer J Clin 61: 69-90, 2011.

2. World Health Organization. World Cancer Report 2014. World Health Organization, Geneva, 2014.

3. Voiculescu SE, Zygouropoulos N, Zahiu CD and Zagrean AM: Role of melatonin in embryo fetal development. J Med Life 7: 488-492, 2014. 
4. Karaaslan C and Suzen S: Antioxidant properties of melatonin and its potential action in diseases. Curr Top Med Chem 15: 894-903, 2015

5. Acuña-Castroviejo D, Escames G, Venegas C, Díaz-Casado ME, Lima-Cabello E, López LC, Rosales-Corral S, Tan DX and Reiter RJ: Extrapineal melatonin: Sources, regulation, and potential functions. Cell Mol Life Sci 71: 2997-3025, 2014.

6. Bubenik GA: Thirty four years since the discovery of gastrointestinal melatonin. J Physiol Pharmacol 59 (Suppl 2): 33-51, 2008.

7. Bubenik GA: Gastrointestinal melatonin: Localization, function, and clinical relevance. Dig Dis Sci 47: 2336-2348, 2002.

8. Kolli VK, Kanakasabapathy I, Faith M, Ramamoorthy H, Isaac B, Natarajan K and Abraham P: A preclinical study on the protective effect of melatonin against methotrexate-induced small intestinal damage: Effect mediated by attenuation of nitrosative stress, protein tyrosine nitration, and PARP activation. Cancer Chemother Pharmacol 71: 1209-1218, 2013.

9. Lissoni P, Barni S, Crispino S, Tancini G and Fraschini F: Endocrine and immune effects of melatonin therapy in metastatic cancer patients. Eur J Cancer Clin Oncol 25: 789-795, 1989.

10. Zhang S, Qi Y, Zhang H, He W, Zhou Q, Gui S and Wang Y: Melatonin inhibits cell growth and migration, but promotes apoptosis in gastric cancer cell line, SGC7901. Biotech Histochem 88: 281-289, 2013.

11. Wang RX, Liu H, Xu L, Zhang H and Zhou RX: Involvement of nuclear receptor RZR/ROR $\gamma$ in melatonin-induced HIF-1 $\alpha$ inactivation in SGC-7901 human gastric cancer cells. Oncol Rep 34 2541-2546, 2015

12. Wang RX, Liu H, Xu L, Zhang $\mathrm{H}$ and Zhou RX: Melatonin downregulates nuclear receptor RZR/ROR $\gamma$ expression causing growth-inhibitory and anti-angiogenesis activity in human gastric cancer cells in vitro and in vivo. Oncol Lett 12: 897-903, 2016.

13. Li W, Fan M, Chen Y, Zhao Q, Song C, Yan Y, Jin Y, Huang Z, Lin $\mathrm{C}$ and $\mathrm{Wu} \mathrm{J}$ : Melatonin induces cell apoptosis in AGS cells through the activation of JNK and P38 MAPK and the suppression of nuclear factor-kappa B: A novel therapeutic implication for gastric cancer. Cell Physiol Biochem 37: 2323-2338, 2015.

14. Carbajo-Pescador S, Ordoñez R, Benet M, Jover R, García-Palomo A, Mauriz JL and González-Gallego J: Inhibition of VEGF expression through blockade of Hifl $\alpha$ and STAT3 signalling mediates the anti-angiogenic effect of melatonin in HepG2 liver cancer cells. Br J Cancer 109: 83-91, 2013.

15. Fan L, Sun G, Ma T, Zhong F and Wei W: Melatonin overcomes apoptosis resistance in human hepatocellular carcinoma by targeting survivin and XIAP. J Pineal Res 55: 174-183, 2013

16. Fan L, Sun G, Ma T, Zhong F, Lei Y, Li X and Wei W: Melatonin reverses tunicamycin-induced endoplasmic reticulum stress in human hepatocellular carcinoma cells and improves cytotoxic response to doxorubicin by increasing $\mathrm{CHOP}$ and decreasing survivin. J Pineal Res 55: 184-194, 2013.

17. Ordoñez R, Carbajo-Pescador S, Prieto-Dominguez N, García-Palomo A, González-Gallego J and Mauriz JL: Inhibition of matrix metalloproteinase-9 and nuclear factor kappa B contribute to melatonin prevention of motility and invasiveness in HepG2 liver cancer cells. J Pineal Res 56: 20-30, 2014.

18. Alvarez-García V, González A, Alonso-González C, Martínez-Campa C and Cos S: Regulation of vascular endothelial growth factor by melatonin in human breast cancer cells J Pineal Res 54: 373-380, 2013.

19. Blask DE, Dauchy RT, Dauchy EM, Mao L, Hill SM, Greene MW, Belancio VP, Sauer LA and Davidson L: Light exposure at night disrupts host/cancer circadian regulatory dynamics: Impact on the Warburg effect, lipid signaling and tumor growth prevention. PLoS One 9: e102776, 2014. doi: 10.1371/journal.pone.0102776.

20. Cos S, Alvarez-García V, González A, Alonso-González C and Martínez-Campa C: Melatonin modulation of crosstalk among malignant epithelial, endothelial and adipose cells in breast cancer (Review). Oncol Lett 8: 487-492, 2014.

21. Proietti S, Cucina A, Dobrowolny G, D'Anselmi F, Dinicola S Masiello MG, Pasqualato A, Palombo A, Morini V, Reiter RJ, et al: Melatonin down-regulates MDM2 gene expression and enhances p53 acetylation in MCF-7 cells. J Pineal Res 57: 120-129, 2014.

22. Cutando A, López-Valverde A, DE Vicente J, Gimenez JL, Carcía IA and DE Diego RG: Action of melatonin on squamous cell carcinoma and other tumors of the oral cavity (Review). Oncol Lett 7: 923-926, 2014
23. Goncalves NN, Rodrigues RV, Jardim-Perassi BV, Moschetta MG, Lopes JR, Colombo J and Zuccari DA: Molecular markers of angiogenesis and metastasis in lines of oral carcinoma after treatment with melatonin. Anticancer Agents Med Chem 14: 1302-1311, 2014.

24. Rodriguez-Garcia A, Mayo JC, Hevia D, Quiros-Gonzalez I, Navarro M and Sainz RM: Phenotypic changes caused by melatonin increased sensitivity of prostate cancer cells to cytokine-induced apoptosis. J Pineal Res 54: 33-45, 2013.

25. Shiu SY, Leung WY, Tam CW, Liu VW and Yao KM: Melatonin MT1 receptor-induced transcriptional up-regulation of p27(Kip1) in prostate cancer antiproliferation is mediated via inhibition of constitutively active nuclear factor kappa B (NF- $\kappa \mathrm{B})$ : Potential implications on prostate cancer chemoprevention and therapy. J Pineal Res 54: 69-79, 2013.

26. Paroni R, Terraneo L, Bonomini F, Finati E, Virgili E, Bianciardi P, Favero G, Fraschini F, Reiter RJ, Rezzani R, et al: Antitumour activity of melatonin in a mouse model of human prostate cancer: Relationship with hypoxia signalling. J Pineal Res 57: 43-52, 2014.

27. Liu H, Xu L, Wei JE, Xie MR, Wang SE and Zhou RX: Role of $\mathrm{CD} 4{ }^{+} \mathrm{CD} 25^{+}$regulatory $\mathrm{T}$ cells in melatonin-mediated inhibition of murine gastric cancer cell growth in vivo and in vitro. Anat Rec (Hoboken) 294: 781-788, 2011

28. Xu L, Jin QD, Gong X, Liu H and Zhou RX: Anti-gastric cancer effect of melatonin and $\mathrm{Bcl}-2, \mathrm{Bax}, \mathrm{p} 21$ and p53 expression changes. Sheng Li Xue Bao 66: 723-729, 2014 (In Chinese).

29. Fakharzadeh SS, Trusko SP and George DL: Tumorigenic potential associated with enhanced expression of a gene that is amplified in a mouse tumor cell line. EMBO J 10: 1565-1569, 1991.

30. Zak K, Pecak A, Rys B, Wladyka B, Dömling A, Weber L, Holak TA and Dubin G: Mdm2 and MdmX inhibitors for the treatment of cancer: A patent review (2011-present). Expert Opin Ther Pat 23: 425-448, 2013.

31. Shaikh MF, Morano WF, Lee J, Gleeson E, Babcock BD, Michl J, Sarafraz-Yazdi E, Pincus MR and Bowne WB: Emerging role of MDM2 as target for anti-cancer therapy: A review. Ann Clin Lab Sci 46: 627-634, 2016

32. He J, Zhu G, Gao L, Chen P, Long Y, Liao S, Yi H, Yi W, Pei Z, $\mathrm{Wu}$ M, et al: Fra-1 is upregulated in gastric cancer tissues and affects the PI3K/Akt and p53 signaling pathway in gastric cancer. Int J Oncol 47: 1725-1734, 2015.

33. Eischen CM and Lozano G: p53 and MDM2: Antagonists or partners in crime? Cancer Cell 15: 161-162, 2009.

34. Nakajima N, Ito Y, Yokoyama K, Uno A, Kinukawa N, Nemoto N and Moriyama M: The expression of murine double minute 2 (MDM2) on Helicobacter pylori-infected intestinal metaplasia and gastric cancer. J Clin Biochem Nutr 44: 196-202, 2009.

35. Günther T, Schneider-Stock R, Häckel C, Kasper HU, Pross M, Hackelsberger A, Lippert H and Roessner A: Mdm2 gene amplification in gastric cancer correlation with expression of Mdm2 protein and p53 alterations. Mod Pathol 13: 621-626, 2000.

36. Sun LP, Jiang NJ, Fu W, Xue YX and Zhao YS: Relationship between gastric cancer and gene amplification of p14 and mdm2. Ai Zheng 23: 36-39, 2004 (In Chinese).

37. Manfredi JJ: The Mdm2-p53 relationship evolves: Mdm2 swings both ways as an oncogene and a tumor suppressor. Genes Dev 24: $1580-1589,2010$

38. Carter S, Bischof O, Dejean A and Vousden KH: C-terminal modifications regulate MDM2 dissociation and nuclear export of p53. Nat Cell Biol 9: 428-435, 2007.

39. Lohrum MA, Woods DB, Ludwig RL, Bálint E and Vousden KH: C-terminal ubiquitination of $\mathrm{p} 53$ contributes to nuclear export. Mol Cell Biol 21: 8521-8532, 2001.

40. Zauberman A, Barak Y, Ragimov N, Levy N and Oren M: Sequence-specific DNA binding by p53: Identification of target sites and lack of binding to $\mathrm{p} 53$ - MDM2 complexes. EMBO J 12: 2799-2808, 1993

41. Poyurovsky MV, Katz C, Laptenko O, Beckerman R, Lokshin M, Ahn J, Byeon IJ, Gabizon R, Mattia M, Zupnick A, et al: The $\mathrm{C}$ terminus of p53 binds the N-terminal domain of MDM2. Nat Struct Mol Biol 17: 982-989, 2010.

42. Cross B, Chen L, Cheng Q, Li B, Yuan ZM and Chen J: Inhibition of p53 DNA binding function by the MDM2 protein acidic domain. J Biol Chem 286: 16018-16029, 2011.

43. Biderman L, Poyurovsky MV, Assia Y, Manley JL and Prives C: $\mathrm{MdmX}$ is required for $\mathrm{p} 53$ interaction with and full induction of the Mdm2 promoter after cellular stress. Mol Cell Biol 32: $1214-1225,2012$ 
44. Bond GL, Hu W, Bond EE, Robins H, Lutzker SG, Arva NC, Bargonetti J, Bartel F, Taubert H, Wuerl P, et al: A single nucleotide polymorphism in the MDM2 promoter attenuates the p53 tumor suppressor pathway and accelerates tumor formation in humans. Cell 119: 591-602, 2004.

45. Bond GL, Hu W and Levine A: A single nucleotide polymorphism in the MDM2 gene: From a molecular and cellular explanation to clinical effect. Cancer Res 65: 5481-5484, 2005.

46. Ofir-Rosenfeld Y, Boggs K, Michael D, Kastan MB and Oren M: Mdm2 regulates p53 mRNA translation through inhibitory interactions with ribosomal protein L26. Mol Cell 32: 180-189, 2008.

47. Mayo LD and Donner DB: A phosphatidylinositol 3-kinase/Akt pathway promotes translocation of Mdm2 from the cytoplasm to the nucleus. Proc Natl Acad Sci USA 98: 11598-11603, 2001.

48. Zhou BP, Liao Y, Xia W, Zou Y, Spohn B and Hung MC: HER-2/neu induces p53 ubiquitination via Akt-mediated MDM2 phosphorylation. Nat Cell Biol 3: 973-982, 2001. Nat Cell Biol 3: 973-982, 2001

49. Gottlieb TM, Leal JF, Seger R, Taya Y and Oren M: Cross-talk between Akt, p53 and Mdm2: Possible implications for the regulation of apoptosis. Oncogene 21: 1299-1303, 2002.

50. Jones SN, Hancock AR, Vogel H, Donehower LA and Bradley A: Overexpression of $\mathrm{Mdm} 2$ in mice reveals a p53-independent role for Mdm2 in tumorigenesis. Proc Natl Acad Sci USA 95: $15608-15612,1998$.

51. McDonnell TJ, Montes de Oca Luna R, Cho S, Amelse LL, Chavez-Reyes A and Lozano G: Loss of one but not two mdm2 null alleles alters the tumour spectrum in p53 null mice. J Pathol 188: 322-328, 1999.

52. Dobbelstein $M$, Wienzek S, König $C$ and Roth J: Inactivation of the p53-homologue p73 by the mdm2-oncoprotein. Oncogene 18: 2101-2106, 1999 .

53. Zeng X, Chen L, Jost CA, Maya R, Keller D, Wang X, Kaelin WG Jr, Oren M, Chen J and Lu H: MDM2 suppresses p73 function without promoting p73 degradation. Mol Cell Biol 19: 3257-3266, 1999.

54. Gu J, Nie L, Kawai H and Yuan ZM: Subcellular distribution of $\mathrm{p} 53$ and $\mathrm{p} 73$ are differentially regulated by MDM2. Cancer Res 61: 6703-6707, 2001.

55. Watson IR, Blanch A, Lin DC, Ohh M and Irwin MS Mdm2-mediated NEDD8 modification of TAp73 regulates its transactivation function. J Biol Chem 281: 34096-34103, 2006.

56. Cheney MD, McKenzie PP, Volk EL, Fan L and Harris LC MDM2 displays differential activities dependent upon the activation status of NFkappaB. Cancer Biol Ther 7: 38-44, 2008

57. Sun P, Dong P, Dai K, Hannon GJ and Beach D: p53-independent role of MDM2 in TGF-beta1 resistance. Science 282: 2270-2272, 1998.
58. Yam CH, Siu WY, Arooz T, Chiu CH, Lau A, Wang XQ and Poon RY: MDM2 and MDMX inhibit the transcriptional activity of ectopically expressed SMAD proteins. Cancer Res 59: 5075-5078, 1999.

59. Xiao ZX, Chen J, Levine AJ, Modjtahedi N, Xing J, Sellers WR and Livingston DM: Interaction between the retinoblastoma protein and the oncoprotein MDM2. Nature 375: 694-698, 1995.

60. Sdek P, Ying H, Zheng H, Margulis A, Tang X, Tian K and Xiao ZX: The central acidic domain of MDM2 is critical in inhibition of retinoblastoma-mediated suppression of E2F and cell growth. J Biol Chem 279: 53317-53322, 2004.

61. Zhou S, Gu L, He J, Zhang H and Zhou M: MDM2 regulates vascular endothelial growth factor mRNA stabilization in hypoxia. Mol Cell Biol 31: 4928-4937, 2011.

62. Thut CJ, Goodrich JA and Tjian R: Repression of p53-mediated transcription by MDM2: A dual mechanism. Genes Dev 11: 1974-1986, 1997.

63. Minsky N and Oren M: The RING domain of Mdm2 mediates histone ubiquitylation and transcriptional repression. Mol Cell 16: 631-639, 2004.

64. Ji W, Ma J, Zhang H, Zhong H, Li L, Ding N, Jiao J and Gao Z: Role of p53 $\beta$ in the inhibition of proliferation of gastric cancer cells expressing wild-type or mutated p53. Mol Med Rep 12: 691-695, 2015

65. Hoffmann I, Draetta G and Karsenti E: Activation of the phosphatase activity of human cdc25A by a cdk2-cyclin E dependent phosphorylation at the G1/S transition. EMBO J 13: 4302-4310, 1994.

66. Zou X, Tsutsui T, Ray D, Blomquist JF, Ichijo H, Ucker DS and Kiyokawa H: The cell cycle-regulatory CDC25A phosphatase inhibits apoptosis signal-regulating kinase 1. Mol Cell Biol 21: 4818-4828, 2001

67. Goloudina A, Yamaguchi H, Chervyakova DB, Appella E, Fornace AJ Jr and Bulavin DV: Regulation of human Cdc25A stability by Serine 75 phosphorylation is not sufficient to activate a S phase checkpoint. Cell Cycle 2: 473-478, 2003.

68. Boutros R, Lobjois V and Ducommun B: CDC 25 phosphatases in cancer cells: Key players? Good targets? Nat Rev Cancer 7: 495-507, 2007.

69. Cheng M, Olivier P, Diehl JA, Fero M, Roussel MF, Roberts JM and Sherr CJ: The p21(Cip1) and p27(Kip1) CDK 'inhibitors' are essential activators of cyclin D-dependent kinases in murine fibroblasts. EMBO J 18: 1571-1583, 1999.

70. Martín V,HerreraF,García-SantosG,AntolínI,Rodriguez-BlancoJ, Medina $M$ and Rodriguez $C$ : Involvement of protein kinase $C$ in melatonin's oncostatic effect in C6 glioma cells. J Pineal Res 43:

71. Rother K, Kirschner R, Sänger K, Böhlig L, Mössner J and Engeland K: p53 downregulates expression of the $\mathrm{G}_{1} / \mathrm{S}$ cell cycle phosphatase Cdc25A. Oncogene 26: 1949-1953, 2007. 